IZA DP No. 7444

Who Chooses Which Private Education?

Theory and International Evidence

Giuseppe Bertola

Daniele Checchi

June 2013 


\title{
Who Chooses Which Private Education? Theory and International Evidence
}

\author{
Giuseppe Bertola \\ EDHEC Business School \\ and CEPR \\ Daniele Checchi \\ University of Milan, \\ IZA and EIEF
}
Discussion Paper No. 7444
June 2013

IZA
P.O. Box 7240
53072 Bonn
Germany

Phone: $+49-228-3894-0$

Fax: +49-228-3894-180

E-mail: iza@iza.org

\begin{abstract}
Any opinions expressed here are those of the author(s) and not those of IZA. Research published in this series may include views on policy, but the institute itself takes no institutional policy positions. The IZA research network is committed to the IZA Guiding Principles of Research Integrity.

The Institute for the Study of Labor (IZA) in Bonn is a local and virtual international research center and a place of communication between science, politics and business. IZA is an independent nonprofit organization supported by Deutsche Post Foundation. The center is associated with the University of Bonn and offers a stimulating research environment through its international network, workshops and conferences, data service, project support, research visits and doctoral program. IZA engages in (i) original and internationally competitive research in all fields of labor economics, (ii) development of policy concepts, and (iii) dissemination of research results and concepts to the interested public.
\end{abstract}

IZA Discussion Papers often represent preliminary work and are circulated to encourage discussion. Citation of such a paper should account for its provisional character. A revised version may be available directly from the author. 
IZA Discussion Paper No. 7444

June 2013

\section{ABSTRACT}

\section{Who Chooses Which Private Education? Theory and International Evidence*}

Private school students do not always perform better in standardized tests. We suggest that this may be explained by choice of private schooling by less capable students in countries where government schools are better suited to talented students. To assess the empirical relevance of this mechanism, we exploit cross-country variation in the PISA 2009 survey of differences between private and state school regarding organizational features that are differently suitable for students with different learning ability. We seek and find evidence of this mechanism's empirical relevance in controlled regressions that treat within-country variation of PISA scores as an indicator of unobserved ability to learn.

JEL Classification: $\quad 121,124$

Keywords: PISA survey, private education, talent, educational background

Corresponding author:

Daniele Checchi

University of Milan

Department of Economics, Management and Quantitative Methods

v. Conservatorio, 7

20122 Milano

Italy

E-mail: daniele.checchi@unimi.it

\footnotetext{
* We are grateful to referees and seminar participants for helpful comments and to Veruska Oppedisano for cooperation at earlier stages of the project.
} 


\section{Introduction}

It might be natural to expect private institutions to deliver better educational outcomes for students who can afford to attend them. In standard economic models, innate or early-life resources are complementary to human capital in the production of life outcomes, and a larger human capital investment is optimal for better-endowed individuals. Since relatively bright individuals are willing to pay for more privately provided human capital than the uniform amount chosen by the political majority for state schools (Stiglitz 1974), expensive private schools can then coexist with cheaper publicly funded ones. Equilibrium sorting is broadly similar if the quality of students itself drives schooling choices and outcomes, in that individual human capital accumulation is positively influenced by peer effects (Epple and Romano, 2004): when schools populated by better students are more attractive, private schools' tuition and admission policies imply that they should educate the more talented segment of the student population. If perfect financial markets could ensure that only talent shapes the distribution of educational investments, then private schools should deliver better educational outcomes, as their students are better and can exploit more educational resources as well as favourable peer effects. In reality, borrowing constraints and other financial market imperfections imply that private schooling choices are also shaped by wealth heterogeneity, and may have undesirable socio-economic implications (see OECD 2012b). Unless wealth and talent are negatively correlated, the larger educational investments or better peer quality that complement richer students' talent still imply that they should do better than government school students (De Fraja 2002).

Private schooling may of course be attractive for reasons other than human capital accumulation, such as an exclusive social climate, or provision of extended hours, better amenities, individual tutoring and counselling, or religious education. Empirically, countryspecific studies find that private education is associated with better future performance in terms of college attendance and labour market prospects in the United States (Evans and Schwab 1995, Rouse 1998, Figlio and Stone 2001) and in the United Kingdom (Green et al. 2011), but private schooling is associated with poorer outcomes in Italy (Bertola and Checchi 2004, Bertola, Checchi and Oppedisano 2007) and Ireland (Pfeffermann and Landsman 2011), while in Chile government and private schools are differently effective for students from different family backgrounds (Contreras, Sepulveda and Busto 2010). Vandenberghe 
and Robin's (2004) cross-country analysis of the 2000 PISA survey finds that private education is associated with higher competencies in some countries, but with lower competencies in others.

In this paper, we relate heterogeneous test performances to the qualitatively different role played various countries by private educational establishments. Like the overall size of the private education sector (West and Woessmann, 2010), its configuration is rooted in each country's historical experience. Not only the amount of resources, but also the organization and objectives of educational processes are qualitatively different in private and government schools. ${ }^{1}$ Private schools cater to students who not only can better afford to pay higher fees, but also find that government schools are less suitable for them. Brunello and Rocco (2008) suggest that students who cannot meet the standards of state school may in some countries choose to pay to obtain degrees and certifications from less demanding private education. Private schools more generally differ from government schools not only because they charge tuition fees, but also because they supply education (and not just degrees) that differs along dimensions that influence the characteristics of the students they attract or select.

Across countries, differences in the relevant features of government and private schools can lead to positive or negative talent sorting, and account for cross-country test performance differences. In countries where historically determined organizational features of government schools provide only basic egalitarian education, and do not reward students' talent, then the private sector attracts better students and displays better achievements (as in United States, Canada, and the United Kingdom, as well as in Brazil and Uruguay). In countries where government schools instead cater to stronger students, the private sector attracts lower quality students (as it is the case of Italy, Israel or Indonesia). Since the student pool of the private sector is then worse than that of government schools, it is not surprising to find empirically that private school students' performance on standardized tests is in these countries worse than that of government school students.

To detect empirically such "product differentiation" across educational establishments, we exploit information about school-level teaching techniques in the PISA international survey data to assess whether educations is organized in ways that complement or substitute student talent in the production of educational outcomes. To characterize the determinants of different

\footnotetext{
${ }^{1}$ Since in British English "public” refers to elite schools that are typically privately funded we use "government" to refer to schools that are publicly funded and/or organized.
} 
choices and outcomes in different countries, we focus on cross-country differentials between government and private schools in terms of features that are more or less suitable for students with heterogeneous learning ability, and we seek evidence of our theoretical perspective's empirical realism in regressions where such features are interacted with indicators of individuals' ability to learn and to choose private schooling.

\section{Modelling private school choice}

We consider school choice by individuals who are heterogeneous both in terms of their "educability" (i.e. ability to take advantage of quality schooling, "talent" for short) and their ability to pay or, more generally, to choose privately managed schools (“wealth”).

We let the outcome of individual $i$ 's attendance of school $j$ depend positively on individual talent $\theta_{i}$ according to

$$
y_{i j}=a_{j}+b_{j} \theta_{i}
$$

where $y_{i j}$ may denote expected earnings, employability, general competences, or other forward-looking individual objectives; the intercept, $a_{j}$, measures school $j$ 's absolute effect, irrespective of individual characteristics; and the slope, $b_{j}$, is an indicator of how strongly educational outcomes depend on individual characteristics, hence of the complementarity between the school's educational techniques and its students' talent. These parameters may differ across educational establishments along a variety of dimensions such as selectivity in admission, curriculum, evaluation criteria, disciplinary climate, educational philosophy, religion or ideology. To characterize the choice between government and private schooling, we let not only the outcome as in (1) but also the cost of school attendance depend on whether $j=1$ indexes a private school or $j=0$ a government school. Formally, we suppose that the cost for individual $i$ of choosing school $j$ is

$$
c_{i j}=\left(1-z_{i}\right) f_{j}
$$

where $f_{1}>f_{0}$ if private schools are more expensive. Financial market imperfections imply that the relevance of these costs depends on an index, denoted $z_{i}$, of individual $i$ 's resources. As discussed in the introduction, privately run schools do not necessarily absorb larger resources, but always differ from government schools in their ability to adjust qualitative 
aspects of education. The functional form in (2) can capture such a mechanism if $f_{1} \neq f_{0}$ represents the extent to which private education management is allowed to differentiate its educational offering from that of government schools, and $z_{i}$ indexes the extent to which a specific individual is able to take advantage of such heterogeneity (for example, because private schools are readily available nearby).

Aiming to maximize $y_{i j}-c_{i j}$, individual $i$ chooses the private $j=1$ school instead of the government $j=0$ school if

$$
a_{1}+b_{1} \theta_{i}-\left(1-z_{i}\right) f_{1}>a_{0}+b_{0} \theta_{i}-\left(1-z_{i}\right) f_{0}
$$

Rearranging this condition to

$$
\left(b_{1}-b_{0}\right) \theta_{i}+\left(f_{1}-f_{0}\right) z_{i}+\left(a_{1}-a_{0}\right)-\left(f_{1}-f_{0}\right)>0
$$

we see that if $b_{1}>b_{0}$, i.e. private schooling is better suited to education of brighter individuals as in Epple and Romano (1998) or in De Fraja (2002), then individuals with higher talent $\theta_{i}$ and higher resources $z_{i}$ are sorted into private schooling.

If instead less expensive government schools reward talent more strongly $\left(b_{1}<b_{0}\right)$, then the higher cost $f_{1}>f_{0}$ of private schooling can be justified by higher talent-independent payoffs $a_{1}>a_{0}$ for students who have sufficiently low talent $\theta_{i}$ and sufficiently large financial resources $z_{i}$ (or, more generally, who are better able to choose privately organized schools if it is advantageous for them to do so). When $b_{1}<b_{0}$, therefore, students who enrol in private schools have lower talent: their performance may therefore be worse even when larger resources expended in their education, and especially likely to be lower when private schools are no more expensive than government schools but exploit their autonomy so as to be especially well suited to low-talent individuals.

In this simple choice model, all school features that influence learning outcomes are summarized by the parameters of the choice criteria. Private schools are attended by richer students if they are more expensive, but need not attract better students if government schools cater to high-talent students. We will study below how empirical indicators of school and student heterogeneity contribute to shaping the talent pool selected into government and private schools. As we do so, we will need to keep in mind that the model does not explicitly 
account for other potentially relevant determinants of government/private choices, such as the availability of religious education, luxurious facilities, and more general features that need not directly bear on educational outcomes, but may vary along both individual and cross-country dimensions.

The model's parameters, and the empirical indicators considered below, can instead represent well the organizational features that play a more relevant role in determining educational outcomes (Woessmann 2003, Hanushek, Link and Woessmann 2011), as well as the peer effects emphasized by Epple and Romano (1998) and Epple, Figlio and Romano (2004): while evidence from the US suggests that private schools differentiate themselves from government schools that are not selective and use a teaching approach suitable for low-talent students, elsewhere government school may provide education suitable for high-talent students, as in the academic track of Continental European systems, and favourable peer effects.

School funding could also be quantitatively different across government and private schools to a different extent in different countries, but there is little or no evidence of relationships between the level of spending and students' achievement at primary and secondary school levels (Hanushek, 1986). A potentially more relevant shortcoming of the model's simple structure is the fact that its ex-ante perspective neglects issues of effort choice and asymmetric information on talent. MacLeod and Urquiola (2009) have shown that if schools select students, and talent is revealed by entrance exams, then students admitted to selective institutions have lower incentives to accumulate skills. This may provide an alternative explanation for worse performance of students admitted in selective private colleges at least in developing countries like India (Rubinstein and Sekhri 2008), or in situations like that of Chile where, after introduction of vouchers in 1981, up to $55 \%$ of students were attending a private institution, without any effect on average competencies (Contreras, Sepulveda and Busto 2010).

\section{Data and descriptive statistics}

The mechanisms we focus on are certainly also at work inside each country, both across vocational and academic tracks, and across more or less expensive and demanding schools. Empirical analysis of international data cannot exploit the rich information that is sometimes available to country-specific studies of the extent to which sorting of students across more or 
less selective and resource-rich post-secondary institutions may explain their different educational and labour market performance. Even suggestive evidence from a more general setting can be preferable to precise estimation in very specific circumstances, however, and the international dimension is a source of observable variation in predetermined countryspecific educational system features.

We consider empirical indicators of government vs. private schooling differences across the countries and regions covered by the 2009 Program for International Student Assessment (PISA) survey, documented in OECD (2012a). This survey, repeated every three years, provides an internationally comparable assessment of reading, math and science competences of 15 year old students. It also gathers from students, parents, and school heads a wealth of additional information regarding students' individual characteristics, family backgrounds, and schools' resources endowment and educational practices.

PISA 2009 data are available for 72 countries or sub-national units. The data set, while very detailed, is not ideal for our purpose of assessing the empirical relevance of qualitative selfsorting effects on average school performance. In the simple model of Section 2, private schooling may be more expensive for its users than government schooling, and its educational offer may be more or less strongly complementary to student talent. Two survey questions to school heads collect relevant information.

First, we know whether the school is autonomous from central government because it is managed by non-government organizations or other private institutions. Table 1 reports the numbers of students surveyed in government and private schools, identifying the latter as those that are managed independently from the government, regardless of whether they also receive most of their funding from non-government sources. In total, there are observations from 18029 schools and 476980 student records, some of which will have to be dropped because of missing values for variables we include in our specifications. ${ }^{2}$ As defined, private schools enrol approximately 20 percent of the student population on average. They attract less than 10 percent of students in United Kingdom, United States, Germany, and more than 30 percent in Chile, Indonesia, Spain, Ireland and Netherlands. As in the OECD (2012b) study of socio-economic stratification across government and private school systems, this definition is

\footnotetext{
${ }^{2}$ The complete PISA 2009 file contains 515858 student records from 18641 schools. We drop all observations from France and Moldova, where no information is available regarding whether schools are public or private, and 23060 observations of students who are 15 year old but are attending grades that differ from the modal grade by more than one year.
} 
appropriate for the purpose of detecting differences rooted in private schools' ability to manage resources flexibly, whether in order to offer more efficient and cost-effective services, or in order to cater to specific student body characteristics.

Second, we know how much of the school's funding originates from the government, from student fees, or from benefactors. Fewer schools are classified as "private" on the basis of whether they receive most of their funding from non-government sources. While this alternative definition should in principle be more restrictive, in the data the two definitions overlap: a non-negligible number of government-controlled schools are funded by fees to a larger extent than private schools in the same countries, presumably because of geographical or field heterogeneity. For our purposes, the definition of "private" in terms of managerial autonomy well suited to capture the extent to which private schools may cater to differently talented students, even when the costs are the same, and makes it possible to exploit international variation across a larger number of countries (essentially all privately managed schools are fully funded by the government in Austria, Czech Republic, Finland, Germany, Hungary, Iceland, Latvia, Lithuania, Netherlands, Norway, Slovak Republic, Serbia, Slovenia, and Sweden).

The results reported in the rest of the paper use management as the criterion for the government vs. private classification, and include tuition fee information to control for funding variation. ${ }^{3}$ Since the geographical location of schools is not recorded, and not all school are surveyed, it is not possible to assess how costs and other school features influence private school enrolment within each individual's choice set. ${ }^{4}$ Like OECD (2012b), therefore, we exploit the variation observed in the characteristics of private and government school at the level of the countries (or, in a limited number of cases, sub-national regions) where the survey was administered. We use the school-level information on the budget portions drawn from private and government sources to construct a country- and school-type specific indicator of user costs,

(F) Fees: the percentage of school funding from fees or charges paid by parents.

\footnotetext{
${ }^{3}$ The parental portion of the survey, administered in very few countries, gathers often missing information about the direct cost of schooling for country specific income brackets (variable pa12q01). While that cost is higher in each country for reporting households with students in private schools, it is not comparable across countries.

${ }^{4}$ As in e.g. Martínez-Mora (2006), who finds that low-quality private schools exist in US localities where low property tax revenues support only low-quality public schools.
} 
The exact definition of this variable is provided in the legend of Figure 1, which plots against it country-specific average differences between private and government schools of the mathematics, literacy, and science PISA test scores (each normalized on a common scale with a procedure documented in OECD 2012a). If the best students were selected into a private sector that supplies better albeit more expensive education, PISA scores differentials should all be positive, and more so where Fees differentials are large. In the data, the relationship between the available indicators is rather flat and noisy. And while private school PISA scores are higher in most countries, notably in Anglo-Saxon countries (United States, United Kingdom, Canada, Australia, and New Zealand) where private education is widely thought to provide better education, in about a fifth of the countries government schools have better PISA test scores than private schools.

If differently able students are sorted into government and private education, of course, it is not necessarily appropriate to interpret test scores as a measure of school performance. The PISA test measures each student's “ability to apply the knowledge and skills learned at school to real-life challenges” at age 15: like the outcome $y_{i j}$ in equation (1), the test score combines individual characteristics (that might be innate or result from previous life experiences) with school-specific features that, in most countries, have operated only for one or two years by the time the test is taken. Much of the test score differential across government and private schools may indeed be driven by the different ability of their students, rather than by the effects the small amount of heterogeneous education already experienced at test time.

The PISA data offers some direct information on the determinants of enrolment choices. In the 2009 survey we analyze, parents in some countries were asked to indicate reasons they chose the school their children were attending. In many of the 15 countries where such data are available, safety and pleasantness of the environment are the most typical reasons for choosing private schools. Academic standards or reputation (and not only geographical proximity, ideology, special programs, and past attendance by other family members) appear relevant only in New Zealand, Hungary, and Qatar. ${ }^{5}$ While these data confirm that self-sorting of students into private schools is not always motivated by better academic quality, they are very scarce and noisy: the parental survey was carried out in only one Anglo-Saxon country

\footnotetext{
${ }^{5}$ In Pisa 2003 a similar question was asked to the students themselves in all countries. In Italy, Austria, and Japan "special programs" were the more prominent answers; in Canada, Germany and UK, "better quality education” was mentioned most often.
} 
(New Zealand), and self-declared motivations may not truthfully reveal that remedial features were the reason for the family's choice of private schooling.

For our purpose of identifying structural determinants of student sorting into private schooling, we prefer to focus on the information provided by the PISA survey on schools' educational techniques. A large amount of school-level information is available on many organizational aspects that appear well suited to education of high-ability individuals, or to strengthening the educational outcomes of less talented students. We proceed to consider some potentially useful such indicators (full definitions can be found in the legends of Figures 2a-f):

$\left(\mathrm{R}_{1}\right)$ Selectivity, a gauge of the role of previous academic performance in school admission.

$\left(\mathrm{R}_{2}\right)$ Accountability, in terms of the availability of comparative information on the school's performance.

$\left(\mathrm{R}_{3}\right)$ Low Pressure to perform, an index of weak concerns about academic standards on the part of parents.

$\left(\mathrm{R}_{4}\right)$ Repeaters, the fraction of students repeating a year in the school.

$\left(\mathrm{R}_{5}\right)$ Good Discipline, an index of infrequent absences and other disruptive behaviour.

$\left(\mathrm{R}_{6}\right)$ Autonomy, a measure of the extent to which the school chooses its own curriculum and educational techniques.

Across countries, the average among private schools of each school feature is significantly and positively correlated with the average of the same feature among government schools. ${ }^{6}$ This unsurprisingly indicates that country-specific features (such as the prevalence of vocational education, the characteristics of the tax system, and culture) determine the overall characteristics of each country's educational system. The differences in such characteristics across private and government schools, however, offer interesting indications of whether, in each country's specific situation, students for whom government-provided education is less than perfectly suitable, and who are in a position to choose private education instead, are seeking opportunities to express their talent (because government schools cater to low-ability students) or remedial education (when government education is demanding).

\footnotetext{
${ }^{6}$ The cross-country correlation between public and government average Fees is the least significant, at about $2 \%$. All other correlations, whether estimated linearly or in rank terms, have p-values below $0.1 \%$.
} 
To assess the potential relevance of indicators $\mathrm{R}_{1-6}$ to such product differentiation mechanisms, we compute their country-level mean difference across private and government schools. In Figures 2a-f, as in Figure 1, we plot the resulting observations to offer descriptive information, and inspect their bivariate relationship to similarly constructed differences of PISA test scores. In Figure 2a Selectivity differences are positively associated with the differential of PISA performance across private and government schools. This is not surprising, in that enrolment in a selective school is an indication of otherwise unobservable good prior academic performance; however, schools do not need to be selective when their teaching techniques imply that only talented students apply, hence it will be interesting to see whether this positive association survives in the next section's multivariate regressions. School Accountability differences may be a better indicator of talent-complementary school features; in Figure 2b, their bivariate relationship with PISA test score differences is perfectly flat and imprecise. A strong and negative relationship is instead observed in Figure 2c with Low Pressure differences, a very direct indicator of the extent to which schools are expected (by parents) to demand and deliver good educational outcomes. In Figure 2d we see that PISA scores tend to be worse in school segments where Repeaters are more numerous: larger numbers of repeating students could indicate that the students are worse performers, or that they are evaluated more severely; the bivariate relationship displayed in the figure suggests that the former mechanism prevails in the data. Good Discipline indicators need not be related to academic performance in theory, because they may be attractive features independently of whether they foster learning. In practice, we see in Figure 2e that they are strongly and positively related to PISA test performances, indicating that parents want talented children to study in non-disruptive environments, or that discipline indirectly measures teaching features that attracts students who are harder to control as well as to teach. There is also little reason to expect Autonomy, which allow schools to adopt more or less demanding curricula, to be positively or negatively related to academic performance; in fact, Figure $2 \mathrm{f}$ displays a shallow and noisy relationship with test scores.

Our formal empirical work will focus on the difference between such relevant observable features of each country's private and government schools, and especially on the interaction of that difference with individual characteristics, controlling for country fixed effects. To assess the multivariate empirical relevance of these indicators of internationally heterogeneous private vs. government differences in terms of teaching techniques, student selection, and user costs, we proceed to inspect their coefficients' statistical significance and 
sign in regressions aimed at describing how heterogeneous students are sorted into private education.

\section{Regression specification}

The simple model outlined in Section 2 could in principle be estimated on individual data if exogenous determinants of school choice as in (1) were observable, and could be used to model selection effects as in (4). The educational outcome $y_{i j}$ that drives individual choices, however, is realized much later in life than the age at which PISA data are collected. The dataset does include detailed information about students' background, but no obvious empirical counterpart of the theoretical model's exogenous $\theta_{i}$ "talent" is available: previous schooling performance or IQ test scores are not recorded in the PISA survey and, even if they were available, they would not necessarily measure cleanly the exogenous and largely unobservable heterogeneity in each individual's ability to take advantage of challenging education, or need for remedial help. This makes those data poorly unsuitable to model selection, as illustrated by the very mixed results of Vandenberghe and Robin's (2004) efforts to use individual background variables as instruments in estimating the effects of private schooling on PISA test performance.

In what follows, we use the admittedly imprecise country-level information discussed in Section 3 to try and disentangle the interplay of individual and school features in determining observed private school enrolment choices. As an empirical counterpart of the choice criterion (4), we consider the linear (for simplicity) probability model

$$
p_{i}=\Delta b_{c} \theta_{i}+\Delta f_{c} z_{i}+\Delta a_{c}-\Delta f_{c}+\varepsilon_{i}
$$

where $p_{i}=1$ if individual $i$ is observed attending a private school in country $c, p_{i}=0$ if individual $i$ is attending a government school instead. An empirical counterpart of the theoretically relevant differences $\Delta b_{c}=b_{1}-b_{0}$ and $\Delta f_{c}=f_{1}-f_{0}$ can be constructed (as we will do shortly) from the country-level indicators discussed in Section 3 above, which can be viewed as predetermined with respect to individual choices within each country. To estimate (5), empirical counterparts are also needed for each individual's "ability to learn” $\theta_{i}$ and "ability to choose private" $z_{i}$ : these conceptually distinct dimensions of individual 
heterogeneity are not directly observable, and any implementation of equation (5) needs to approximate them with variables that need not be independent of the error term $\varepsilon_{i}$.

To address this issue we suppose that, like the life outcome modelled in equation (1), the observed test performance may depend on both country- and individual-specific factors as well as on intrinsic unobservable talent, we suppose that the latter is linked to the PISA score by a relationship in the form

$$
\theta_{i}=\alpha_{c}+\beta_{c} P I S A_{i}+\sum_{j=1}^{J} \beta_{c j} X_{j i}
$$

This very general notation allows individual characteristics indexed by $j$ to shape the inference that one may draw on $\theta_{i}$ from the test outcomes in ways that may depend on the country $c$ where they are observed. Crucially, it assumes that, within each country, neither the slope nor the level of this relationship depend on whether student $i$ is enrolled in a government or in a private school. Otherwise, in the absence of exogenous observable determinants of enrolment choices it would not be possible to disentangle the obvious circularity of possible effects, and assess whether talent influences school choice or the chosen school influences performance.

Our maintained identifying assumption is that most if not all of the variation in PISA scores unaccounted for by covariates reflects factors that also determine school choice, rather than the effects of the school where students are enrolled. This perspective on the data is certainly very different from that of studies viewing the PISA score as an outcome of interest when assessing school effectiveness (Vandenberghe and Robin, 2004). While not testable, it appears at least as plausible as other identification strategies, not only because the school has been operating for only one or two years at the time when the survey is administered, but also because it presumably was not chosen for the purpose of doing well on that test: any direct influence of the school on the PISA score, for example through an educational climate that motivates students to do well on anonymous tests, should not matter for the choice we are modelling as much as its the longer-run, and unobserved, influence on life outcomes. 
Next, we specify a similarly flexible relationship between each individual's ability to pay (or to choose a privately managed school) and a list of observable individual characteristics: ${ }^{7}$

$$
z_{i}=\gamma_{c}+\sum_{j=1}^{J} \delta_{c j} X_{j i}
$$

Inserting (6) and (7) in (5) we obtain

$$
p_{c i}=\Delta b_{c} \beta_{c} P I S A_{i}+\sum_{j=1}^{J}\left(\beta_{c j} \Delta b_{c}+\delta_{c j} \Delta f_{c}\right) X_{i j}+\Delta b_{c} \alpha_{c}+\Delta a_{c}+\left(\gamma_{c}-1\right) \Delta f_{c}+\varepsilon_{i}
$$

and we proceed to discuss how a regression of this type may help assess the role of international school-system heterogeneity in determining private school enrolment.

To this end, we specify an empirical counterpart for country-level differences in talent-related schooling features in the form of a weighted linear combination of the country-level indicators introduced in Section 3 and defined and displayed in Figures 2a-f,

$$
\Delta b_{c}=\sum_{k=1}^{6} \lambda_{k} \Delta \bar{R}_{k c}
$$

and we similarly suppose that the theoretical cost differential is related as in

$$
\Delta f_{c}=\mu \Delta \bar{F}_{c}
$$

to the fees indicator introduced in Section 3 and documented in Figure 1. The slopes of these relationships can be estimated from cross-country data if cross-country parameter heterogeneity is suitably restricted. Inserting (9) and (10) in (8) yields an equation that relates observed private school enrolment choices to interactions between the individual PISA score and country-specific differences of schooling features that are more or less attractive for more or less talented students. If as in (9) each schooling feature $k$ influences the theoretical talentcomplementarity parameter $b$ in the same way across countries (i.e., $\lambda_{k}$ is not allowed to vary with $c$ ), an individual's better ability to learn as indicated by higher PISA scores should be more strongly associated with private school enrolment within countries where private schools appear more suitable for good students than government schools.

In the data, this is the case when $\Delta \bar{R}_{x c}$ is strongly positive for schooling features for which $\lambda_{x}>0$ is theoretically plausible, or very negative for features that are more suitable for weak

\footnotetext{
${ }^{7}$ By construction, (6) and (7) allow the two choice-relevant characteristics of each individual to be correlated through observables that appear in both expressions with non-zero coefficients. Correlation through unobservables would of course be problematic.
} 
students, so that $\lambda_{x}<0$. Since this implication is drawn from a specification that does not allow the relationship between PISA score and unobserved ability to differ across government and private schools within each country, estimates of these effects are of course biased by any choice-and-PISA-relevant effect that the chosen school already had at the time of PISA testing.

Besides interactions between PISA scores and country-level schooling features, estimable regressions in the form (8) should include fixed country effects. These can hardly be omitted, in light of the very wide differences in such factors as the average cost of private education and the intensity of any religious connotation or contextual effects, and absorb the $\Delta b_{c} \alpha_{c}+\Delta a_{c}+\left(\gamma_{c}-1\right) \Delta f_{c}$ term in (8), hence the main effects of all country-specific privategovernment difference indicators. Estimable counterparts of (8) should also in principle include all individual level covariates $X_{i j}$ that may be expected to be related to each student's ability to learn (and to do well on the standardized tests), and/or to the family's ability to enrol him or her in a private school. In the most general models of this type, the slope parameters

$$
\beta_{c j} \Delta b_{c}+\delta_{c j} \Delta f=\beta_{c j} \sum_{k=1}^{6} \lambda_{k} \Delta \bar{R}_{k c}+\delta_{c j} \mu \Delta \bar{F}_{c}
$$

of any potentially relevant covariate $j$ should be allowed to differ across countries in unrestricted ways, and would absorb all the slope variation theoretically implied by countrylevel schooling features and fees differences. It would be inappropriate to restrict the coefficients of any individual observable characteristic $X_{j i}$ to be the same across countries: not only because the parameters linking those characteristics to the choice-relevant variables $\theta_{i}$ and $z_{i}$ may be heterogeneous across countries (a concern that may be partly alleviated by the fact that many observables can be expressed in the form of OECD-normalized indexes); but also because our theoretical perspective implies that those underlying variables have different implications for private school choice in different countries.

Restricting not only $\lambda_{k}$ but also $\mu$ to be the same across countries may make it possible to isolate the average influence of school-system features on enrolment choice through their interaction with individual variables. The coefficients of interactions between school-system features and individual observable characteristics, however, generally estimate a mix of the sorting effects of interest, and of those characteristic's relevance to the underlying abilities to learn and to choose private education. Additional identifying assumptions are needed to 
isolate and interpret some country-specific sources of slope heterogeneity. To see this, suppose covariate $j=x$ could be excluded from the ability-to-learn relationship (6), where $\beta_{c x}=0$ for all $c$. This would make it possible to detect that variable's influence on ability to pay as in (7), at least on a cross-country average basis, and to infer from the interaction coefficient of $X_{x i}$ and $\Delta \bar{F}_{c}$ the role of individual ability to pay in determining private school choices. Symmetrically, excluding some other covariate from any relevance to ability to pay would make it possible to assess the ability-to-learn relevance of specific schooling features from their interaction with that covariate.

\section{Regression results}

We proceed to explore the empirical fit of our perspective in cross-country pooled individual choice regressions that, as in (8), (9), (10), model the internationally heterogeneous relevance of talent and ability to pay in private school choice as a linear combination of the countryspecific differences between private and government schools discussed in Section 3. Schoollevel variables need not appear in the specification, not only because they are excluded by our identifying assumption but also because including the characteristics of the school attended by each student would be a source of omitted variable bias when no information is available, at levels of disaggregation lower than that of countries, for the schools that were feasible but rejected alternative choices in each student's choice set. Nevertheless, we report statistics allowing for clustering at the school as well as the country level. Coefficient estimates turn out to appear more precisely estimated when standard errors are only clustered at the country level, so this is a conservative assumption, and may usefully capture second-moment effects of each school's unobserved geographical and socio-economic situation.

The PISA survey collects a large number of individual-level variables, very many if not all of which are potentially related to the family's ability to choose private schooling, to the student's ability to learn, and to other factors that influence enrolment choices. Of course, estimation of specifications in the form of (8), (9), (10) needs to parsimoniously focus on a few such variables of particular interest, because a large number of interacted covariates would not only make estimation too onerous when all available countries are included in the sample, but also yield results that would be very difficult to interpret clearly.

To illustrate our approach and assess its empirical relevance, we consider individual-level variation in five theoretically relevant characteristics as well as in the PISA score: 
$\left(\mathrm{X}_{1}\right)$ Individual Gender (female $=1$ ), which can influence private school choices not only through any relationship to ability-to-learn but also through country-specific cultural and schooling system features (such as different concerns about disciplinary and behavioural environments, or the coeducational character of government schools).

$\left(\mathrm{X}_{2}\right)$ Individual enrolment in a Vocational or pre-vocational programme, coded as 1 when PISA variable iscedo takes values 2 or 3 (rather than $1=$ General education), which can similarly play a role in the determination, within each country, of private school choice by students of different ability.

$\left(\mathrm{X}_{3}\right)$ City size, as a scalar indicator (rather than a set of dummies, to ease estimation and interpretation of interaction coefficients) corresponding to the possible answers to survey question sc04q01. ${ }^{8}$ This is a proxy of availability of private schools, which should make them easier to choose for individuals who find them more suitable than government schools.

Among the many background characteristics that may be relevant to each student's talent as well as to the family's ability choose non-government independently managed schools, we use:

$\left(\mathrm{X}_{4}\right)$ Cultural level, the standardized "Family cultural possessions" index reported in variable cultposs (based on answers given to questions on availability of "Classical literature”, "Books of poetry”, “Works of art.”)

$\left(\mathrm{X}_{5}\right)$ Wealth, the standardized "Family wealth possessions" index reported in variable wealth (based on answers given to questions on availability of "A room of your own”, "A link to the internet”, “A dishwasher”, “A DVD player”, "How many cellular phones”, "How many televisions", "How many computers", "How many cars”, "How many rooms with a bath or shower" and three country-specific items).

Of course, these and others observable household characteristics are all correlated to both the student's ability to learn, $\theta_{i}$ as in (6), and the family's ability to pay, $z_{i}$ as in (7). However,

\footnotetext{
8 "Which of the following definitions best describes the community in which your school is located? $1=\mathrm{A}$ village, hamlet or rural area (fewer than 3000 people); 2=A small town (3000 to about 15000 people); $3=$ A town (15000 to about 100000 people); 4=A city (100000 to about 1000000 people); 5=A large city (with over 1000000 people)."
} 
the two we choose are arguably more cleanly related to those theoretical factors than the other available OECD-standardized indices of family background. ${ }^{9}$

The most general versions of regressions that control for even just these individual variables in country-specific fashion require estimation of several hundred unrestricted nuisance parameters. For this reason, in Table 2 we initially report simpler regressions, aiming to assess the extent to which the interaction effects of interest we detect there (as well as in the bivariate relationships displayed in the figures above) remain sensibly signed and significant in more complex and rigorous specifications.

The regression reported in column (1) of Table 2 models the relationship between private enrolment and individual PISA scores, ${ }^{10}$ allowing its slope to vary across countries in ways explained by interactions with private/government differences of country-level averages of teaching feature indicators. A main effect of the PISA score and country specific intercepts are also included in the regression. Some strongly significant and sensibly signed interaction coefficients convey a message that is broadly similar to, but interestingly different from that of the bivariate relationships displayed in Figures 2a-f. Selectivity is not significant, indicating that schools which offer talent-complementary teaching features do not need to reject poor performers. Accountability, Good Discipline, and Autonomy interaction coefficients are significantly positive, indicating that these features are complementary to the PISA score talent indicator; Low Pressure and Repeaters interaction coefficients are significantly negative instead.

The regression reported in column (2) allows the PISA score and the five $X_{i}$ variables listed above to also enter individual-level regressions with country-specific slopes. This theoretically sensible specification considerably weakens the relationship between private school choices and interactions with PISA scores of country-level indicators of private vs.

\footnotetext{
${ }^{9}$ The "Home educational resources" index (hedres, based on answers given to questions on availability of "A desk to study at", "A quiet place to study", "A computer you can use for school work", "Educational software", "Books to help with school work", "technical reference books", "A dictionary") is related to both financial and cultural resources, and availability of specifically educational resources may be determined by the child's need for help, rather than be a determinant of ability to learn. The "ICT resources at home" index (ictres, based on availability of "Educational software", "A link to the internet", and "How many computers") may also reflect the need for remedial help, or be polluted for the purpose of assessing the family's cultural level by use of internet and computers for entertainment rather than learning purposes.

${ }^{10}$ Measured as the simple average of the science, reading, mathematics test results, each transformed to the PISA scale with a "plausible values" imputation methodology on each of these domains and for sub-domains in science (see OECD 2012a for details).
} 
government school differences. The coefficient of the Repeaters interaction is now insignificantly negative, suggesting that large numbers of held-back students may indicate that the school demands good performance from students; Good discipline, another relatively dubious indicator of talent-complementary school features, is completely insignificant. Low Pressure and Autonomy remain significant, indicating that some theoretically sensible variables do account for a portion of the country-specific variation in the PISA slope as an explanatory variable for private school enrolment. ${ }^{11}$

In column (3), like in column (1), the regression omits country-level covariates in unrestricted form (and controls only for country-specific intercepts and a pooled PISA score main effect) in order to focus on some potentially interesting interactions between country-specific school features and observable individual characteristics other than the PISA score. In this admittedly loose specification, indicators of both Cultural Level and Wealth report significantly positive interactions with Fees, and significantly negative interactions with Low Pressure. The positive interaction between Wealth and Fees suggests that ability to pay plays an important role in determining choice of privately managed schools, and the negative interaction between Cultural Level and Low Pressure (a school feature that is most clearly not complementary to student talent) suggests that, depending on the configuration of each country's school system, that choice need not be positively related to ability to learn. The positive interaction between Cultural Level and Fees, and the negative one between Wealth and Low Pressure, confirm that it is not easy to use observable background characteristics (all of which are correlated to each other and to the underlying theoretically relevant factors) to disentangle ability to pay from ability to learn.

In column (4), in fact, inclusion of individual covariates with country-specific slopes suffices to invert the sign of two of the estimated interactions. In this specification, interactions between some country-specific features and individual covariates absorb part of the variation that was already explained by country-specific slope coefficients in column (2), and do not affect the estimated coefficients of PISA score interactions. In countries where private schools

\footnotetext{
${ }^{11}$ It may be helpful to note that these coefficients are identified by the assumption that the $\lambda$ parameters in (9) are not country-specific, and that the information they convey is the same that could be gathered from the coefficients of a regression of PISA slope coefficients, estimated from country-specific controlled regressions, on the country-specific indicators. Such a two-step approach would require adjustment of coefficient standard errors to account for estimation errors in the dependent variables and, while perhaps more immediately interpretable, it is computationally no less demanding than the one-step estimates we report.
} 
are relatively less demanding, as indicated for example by Low Pressure in this specification, good PISA test performers are less likely to choose them. The sign pattern of the Wealth interaction coefficients is consistent with our theoretical perspective, and their significance confirms the empirical relevance of its sensible implications. Privately managed schooling is chosen by rich families (to an extent determined by country-specific cost differentials), but not necessarily (and even less when they are more expensive) for students who, on the basis of their family's cultural level, appear better able to cope with a demanding learning environment.

This specification arguably implements our theoretical perspective as rigorously as practically possible, and considerably stresses the information content of the data: fewer parameters can be estimated than in column (2), because many interacted variables are dropped due to collinearity. In principle, many other theoretically interesting mechanisms could be detected empirically; in practice, this is far from easy. To try and detect the possible role of City Size in allowing private schools to be chosen, the regression reported in column (5) interacts that variable with the country-specific indicator of Autonomy, but the slope parameter (like the variable itself) is very poorly measured and, while sensibly positive, it is insignificant.

\section{Summary and directions for further research}

We argue in theory that private schools' teaching techniques need not always be complementary to students' ability to learn, so that better students select into private education: when high ability students are well served by government schools, private schools may cater to worse students. Our empirical analysis generalizes and interprets the contrast between country-specific evidence of positive selection into private schooling in the US (as in Epple, Figlio, and Romano 2004) and negative selection in Italy (as in Bertola, Checchi, and Oppedisano 2007). Along the cross-country dimension of the PISA 2009 survey data set, we find that private schools attract more talented students where they are more demanding and less talented students where they specialize in relatively remedial education in the presence of high-quality government school. In terms of features that can be approximately measured on the basis of the information available in the PISA survey, private schools appear better suited to good students in countries like Canada, the United States, and the United Kingdom, where private schools deliver better test performances. In countries such as Italy and Indonesia, conversely, private schools are less attractive for good students than government schools. 
Further research could fruitfully explore in more detail the empirical patterns uncovered by the regressions we report, which are only meant to be illustrative. Analysis of sub-samples of countries may uncover more interpretable information, and could be refined recognizing that the characteristics of private and government schools differ, within countries, across segments defined by city sizes and vocational orientation. While peer effects are difficult to measure reliably, their plausible relevance reinforces the mechanism we focus on since, at any given level of resource expenditure, the relative quality of private and government schools' student bodies should be directly related to that of their educational offering.

It would also be interesting to characterize the historical and political determinants of whether, in each country, the teaching organization of government schools caters to low or high ability students, leaving different market niches to be filled by private schools. The distributional implications of such heterogeneity are of course important, and interact with those of voucher schemes and other policies meant to make private education affordable for poorer families. If liquidity constraints keep poor and talented youth from attending better private schools, then such schemes improve equality of opportunities at the same time as they enhance the productivity of society's educational resources. In countries where high-quality government schools attract the brightest segment of the student pool, conversely, government funding of privately organized education benefits a segment of low-ability students who are not rich or disadvantaged enough to purchase unsubsidized remedial education. While the resulting redistribution across differently wealthy and differently able individuals may be politically attractive in some cases, voucher schemes do not enhance equality of opportunities and the overall efficiency of education systems where governments provide low-cost demanding education. 


\section{References}

Bertola, G., Checchi D. (2004), "Sorting and private education in Italy” in Education, Training and Labour Market Outcomes, ed. by Checchi, D. and Lucifora, C., PalgraveMcMillan.

Bertola, G., Checchi D., Oppedisano V. (2007), "Private School Quality in Italy", Giornale degli Economisti e Annali di Economia, Vol. 66(3): 375-400

Brunello, G., Rocco, L. (2008), "Educational Standards in Private and Public Schools" Economic Journal, vol. 118(533): 1866-1887

Contreras, D., Sepulveda, P., Busto S. (2010) "When Schools Are the Ones that Choose: The Effects of Screening in Chile” Social Science Quarterly, Volume 91(5): 957-976

De Fraja, G. (2002), “The design of optimal educational policies”, Review of Economic Studies, vol. 69: 437-466.

Epple, D., Romano, R. (1998) “Competition between private and public schools, vouchers, and peer-group effects”, American Economic Review, vol. 88(1): 33-62.

Epple, D., Figlio, D., Romano, R. (2004) “Competition between private and public schools: testing stratification and pricing predictions.” Journal of Public Economics 88: 12151245

Evans W., Schwab R. (1995) "Finishing High School and Starting College: do Catholic Schools Make a Difference?", The Quarterly Journal of Economics, Vol. 110(4): 941974

Figlio D., Stone J. (2001) "Can Public Policy Affect Private School Cream Skimming?" Journal of Urban Economics, vol. 49(2): 240-266,

Green F., S.Machin, R.Murphy,Y.Zhu. (2011) “The Changing Economic Advantage from Private Schools.” Economica. 79/316: 658-679

Hanushek, E. (1986), “The Economics of Schooling: Production and Efficiency in Public Schools", Journal of Economic Literature, Vol. 24: 1141-1177

Hanushek, E., Link S., Woessmann, L. (2011) "Does School Autonomy Make Sense Everywhere? Panel Estimates from PISA”. NBER wp.17591

MacLeod, W.B., Urquiola, M. (2009) “Anti-Lemons: School Reputation and Educational Quality”. NBER Working Paper 15112.

Martínez-Mora, F. (2006). “The existence of non-elite private schools” Journal of Public Economics 90 1505-1518. 
OECD (2012a) PISA 2009 Technical Report. Paris: Organization for Economic Cooperation and Development.

OECD (2012b) Public and Private Schools. How management and funding relate to their socio-economic profile. Paris: Organization for Economic Cooperation and Development.

Pfeffermann, D., Landsman, V. (2011). “Are Private Schools Better Than Public Schools? Appraisal for Ireland by Methods for Observational Studies.” mimeo

Rouse, C. (1998) "Private School Vouchers and Student Achievement: An Evaluation of the Milwaukee Parental Choice Program” Quarterly Journal of Economics 113(2): 553-602 Rubinstein, Y., Sekhri S. (2008) “Do Public Colleges in Developing Countries Provide Better Education than Private ones? Evidence from General Education Sector in India.” Virginia Economics Online Papers 375

Stiglitz, J. (1974), “The demand for education in public and private school system”, Journal of Public Economics, vol. 3: 349-385.

Vandenberghe, V., Robin, S. (2004), "Evaluating the effectiveness of private education across countries: a comparison of methods”, Labor Economics, vol. 11(4): 487-506.

West, M.R., Woessmann, L. (2010) 'Every catholic child in a catholic school': Historical resistance to state schooling, contemporary private competition and student achievement across countries.” The Economic Journal, 120 (August): F229-F255

Woessmann, L. (2003) "Schooling Resources, Educational Institutions and Student Performance: the International Evidence", Oxford Bulletin of Economics and Statistics, Vol. 65(2): 117-170 


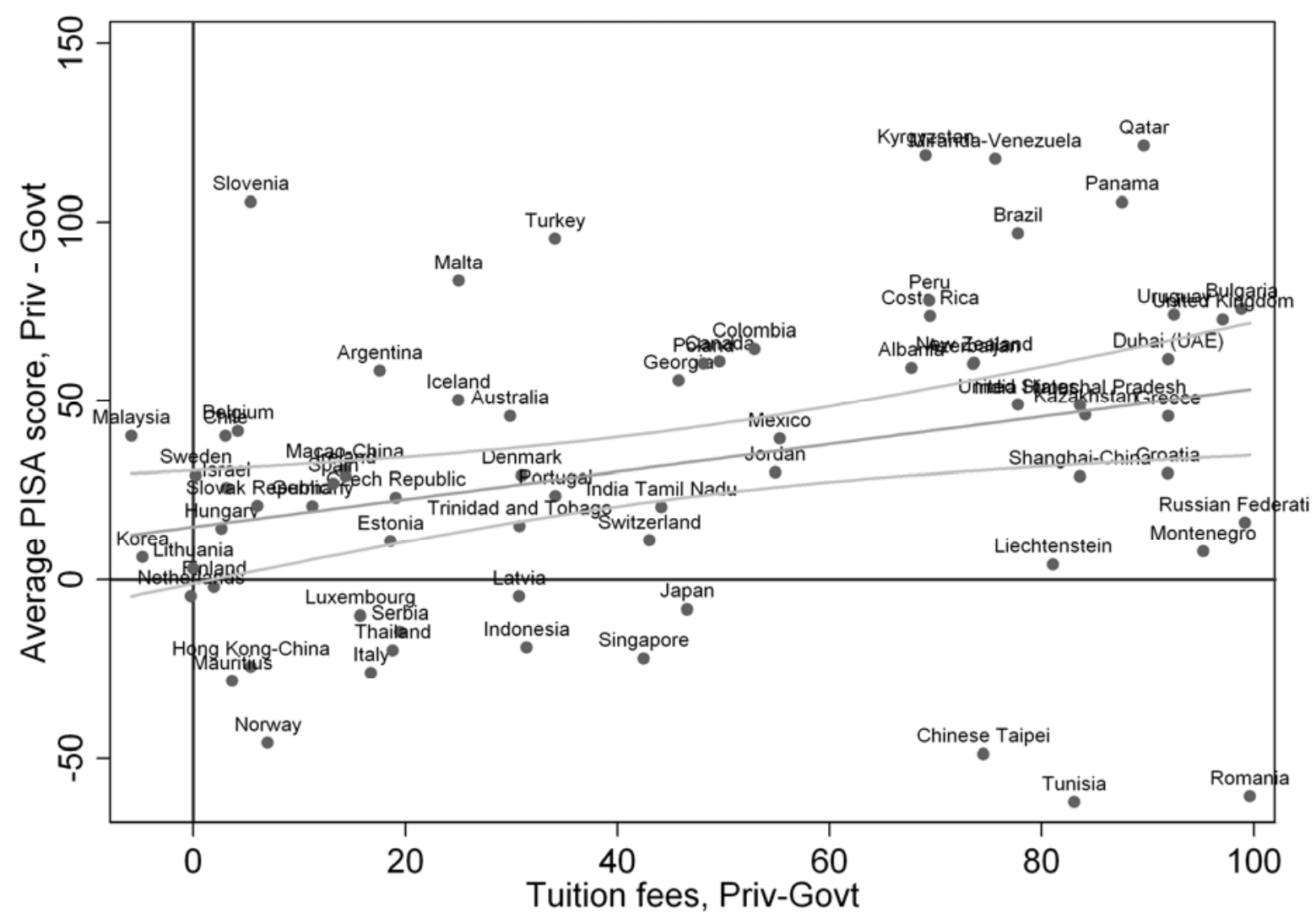

Figure 1. PISA Scores and Fees, country-specific differences between private and government school averages. Vertical axis: difference between the average across all of each country's private school students, and the average across all government school students of PISA scores in mathematics, reading, and science. Horizontal axis: User cost differentials measured from country-specific averages, within each of the private and government sectors, of variable sc03q02, the school manager's answer to survey question “About what percentage of your total funding for a typical school year comes from school fees or school charges paid by parents?” 


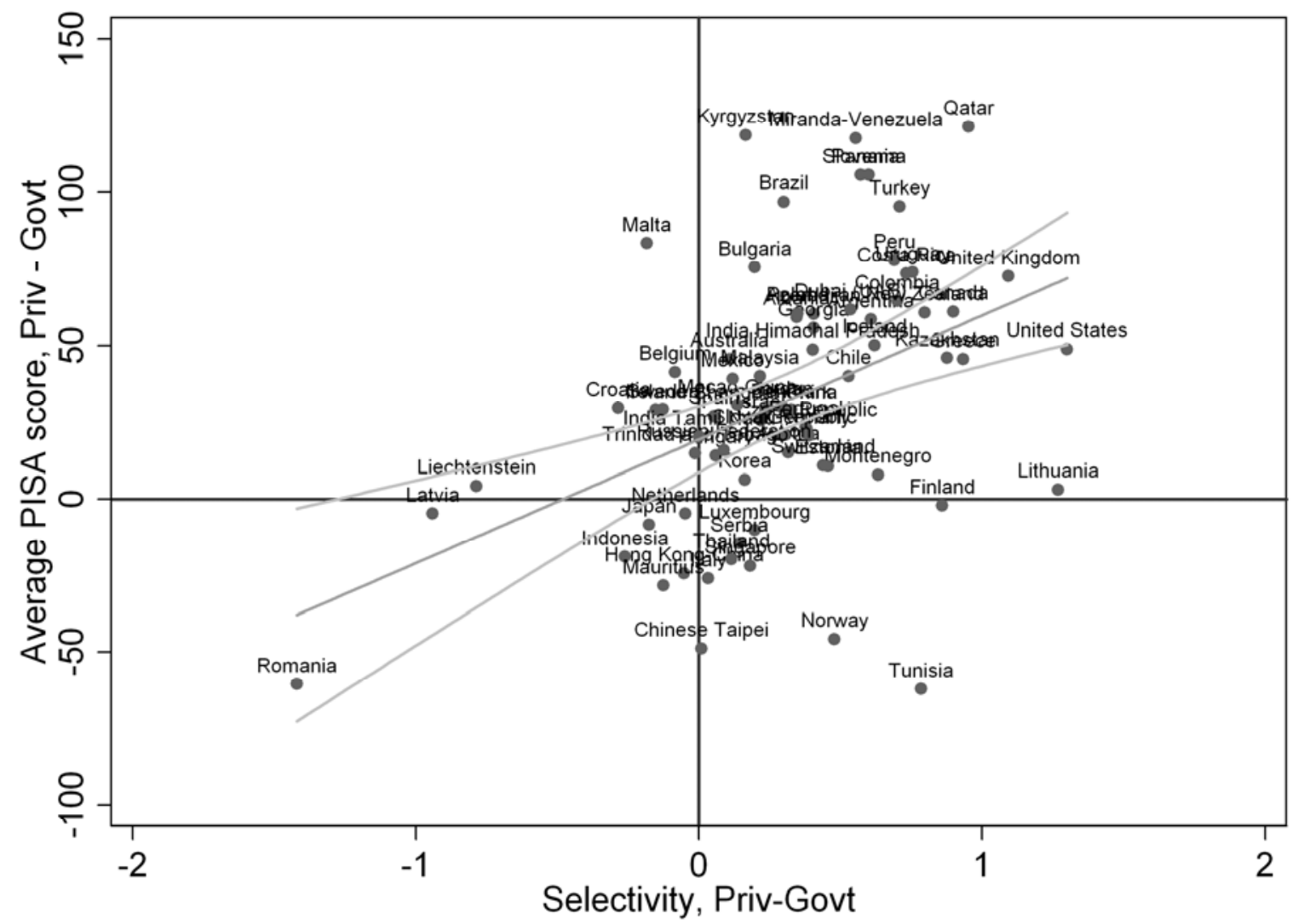

Figure 2a. PISA Scores and Selectivity, country-specific differences between private and government school averages. All observations are plotted along with a linear regression prediction and 95\% mean confidence intervals. Vertical axis: PISA Scores differential as defined in the note to Figure 1. Horizontal axis: Selectivity differential measured from country-specific averages, within each of the private and government sectors, of variable selsch coded to have value 1 for schools where neither students' academic record (including placement tests) and the recommendation of feeder schools are considered for student admittance, 2 for schools considering at least one of these indicators, 3 for schools where at least one of these two factors is a prerequisite for student admittance. 


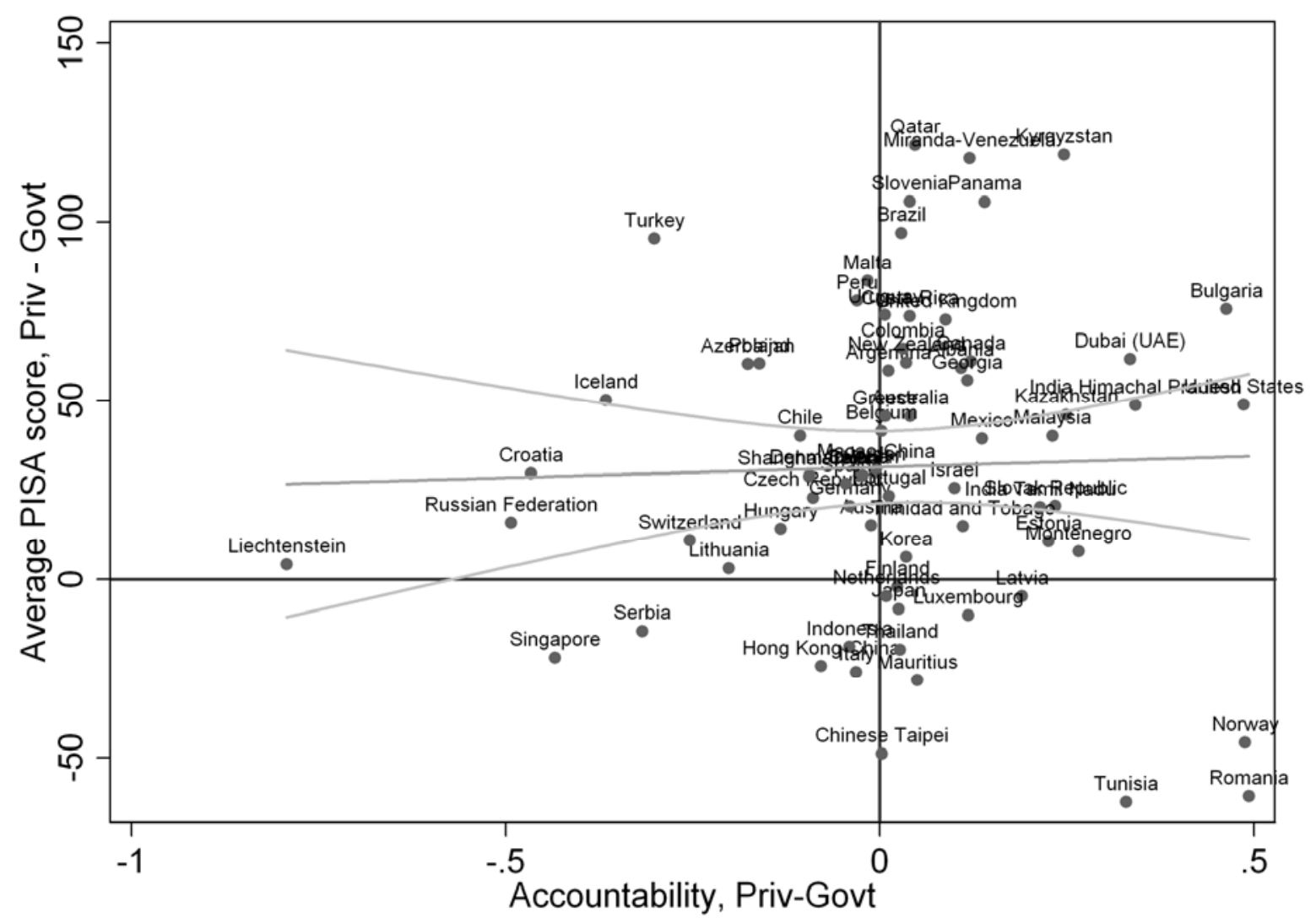

Figure 2b. PISA Scores and Accountability, country-specific differences between private and government school averages. All observations are plotted along with a linear regression prediction and 95\% mean confidence intervals. Vertical axis: PISA Scores differential as defined in the note to Figure 1. Horizontal axis: Accountability differential measured from country-specific averages, within each of the private and government sectors, of variable sc21q03, coded 1 if the school provides information to parents on the academic performance of students as a group relative to students in the same grade in other school. 


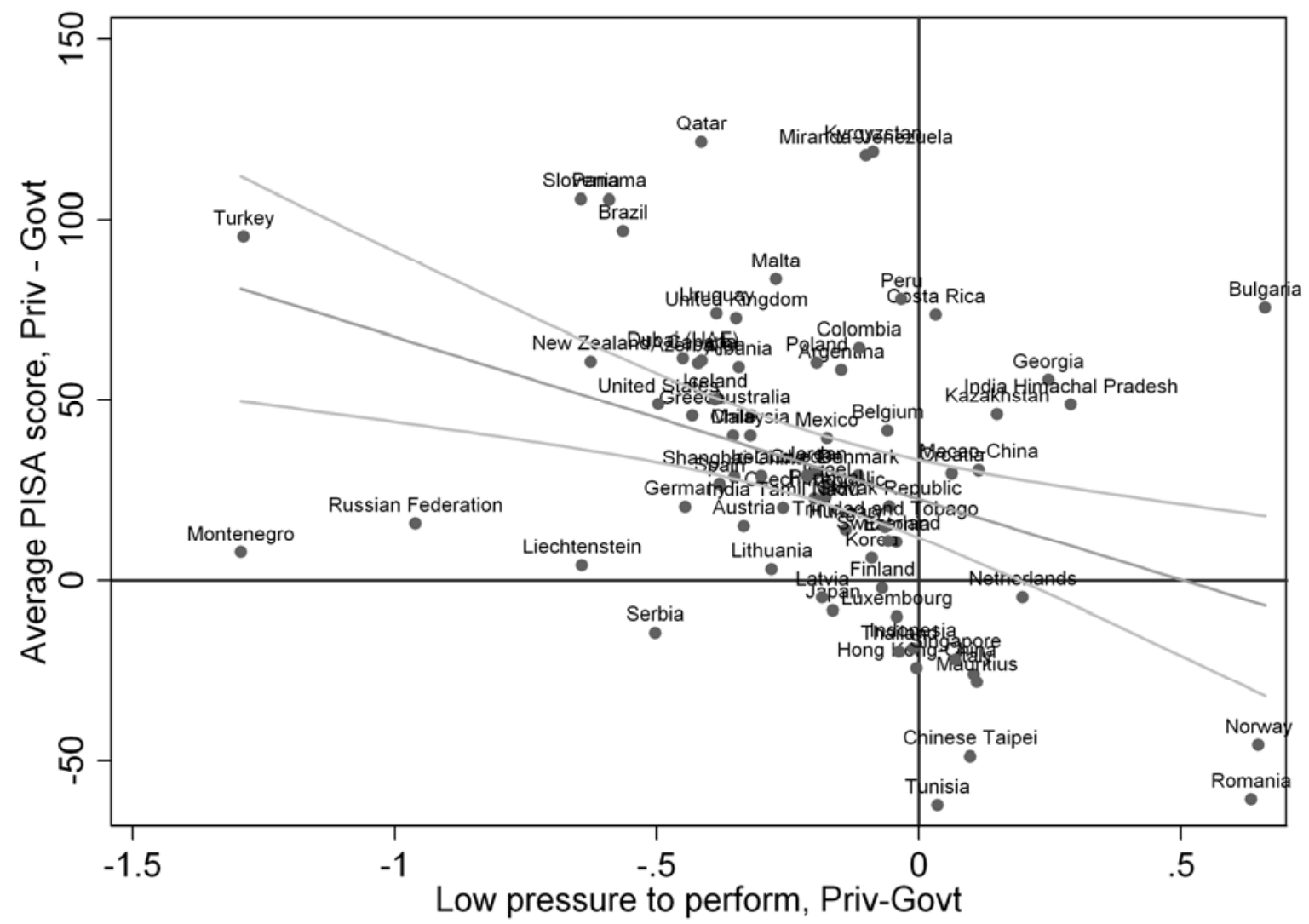

Figure 2c. PISA Scores and Low Pressure, country-specific differences between private and government school averages. All observations are plotted along with a linear regression prediction and 95\% mean confidence intervals. Vertical axis: test scores differential as defined in the note to Figure 1. Horizontal axis: Difference between country-specific averages, within each of the private and government sectors, of variable sc18q01, with values 1 if the school head reports that "there is constant pressure from many parents, who expect our school to set very high academic standards and to have our students achieve them", 2 if "pressure on the school to achieve higher academic standards among students comes from a minority of parents", 3 if "pressure from parents on the school to achieve higher academic standards among students is largely absent.” 


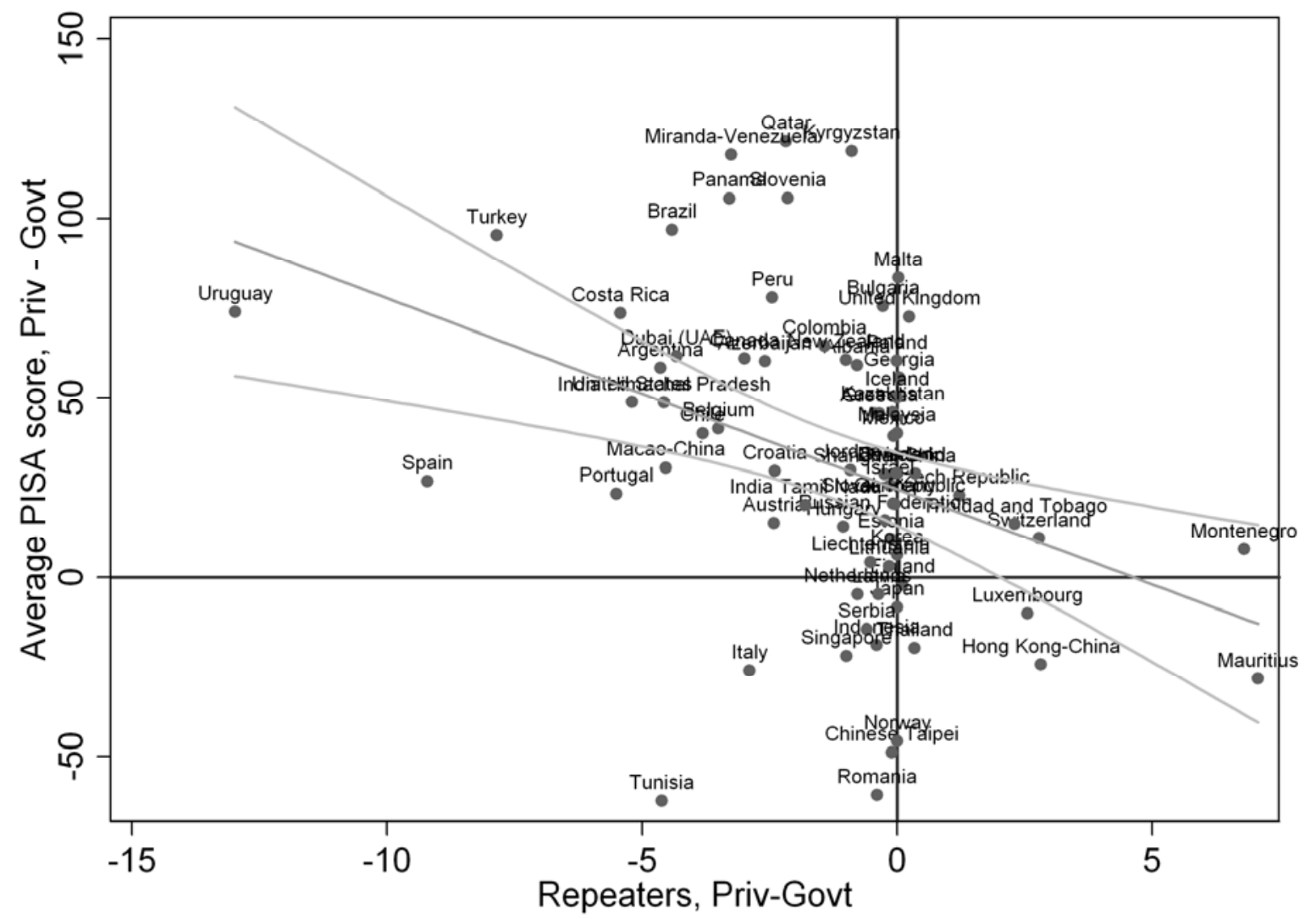

Figure 2d. PISA Scores and Repeaters, country-specific differences between private and government school averages. All observations are plotted along with a linear regression prediction and 95\% mean confidence intervals. Vertical axis: test scores differential as defined in the note to Figure 1. Horizontal axis: Repeaters differential measured from country-specific averages, within each of the private and government sectors, of variable sc07q02 reporting "the approximate percentage of students repeating a grade at ISCED 3 in this school last year”. Missing information for Iceland, Japan, Korea, Malaysia, Norway, Poland (only private) is set equal to zero. 


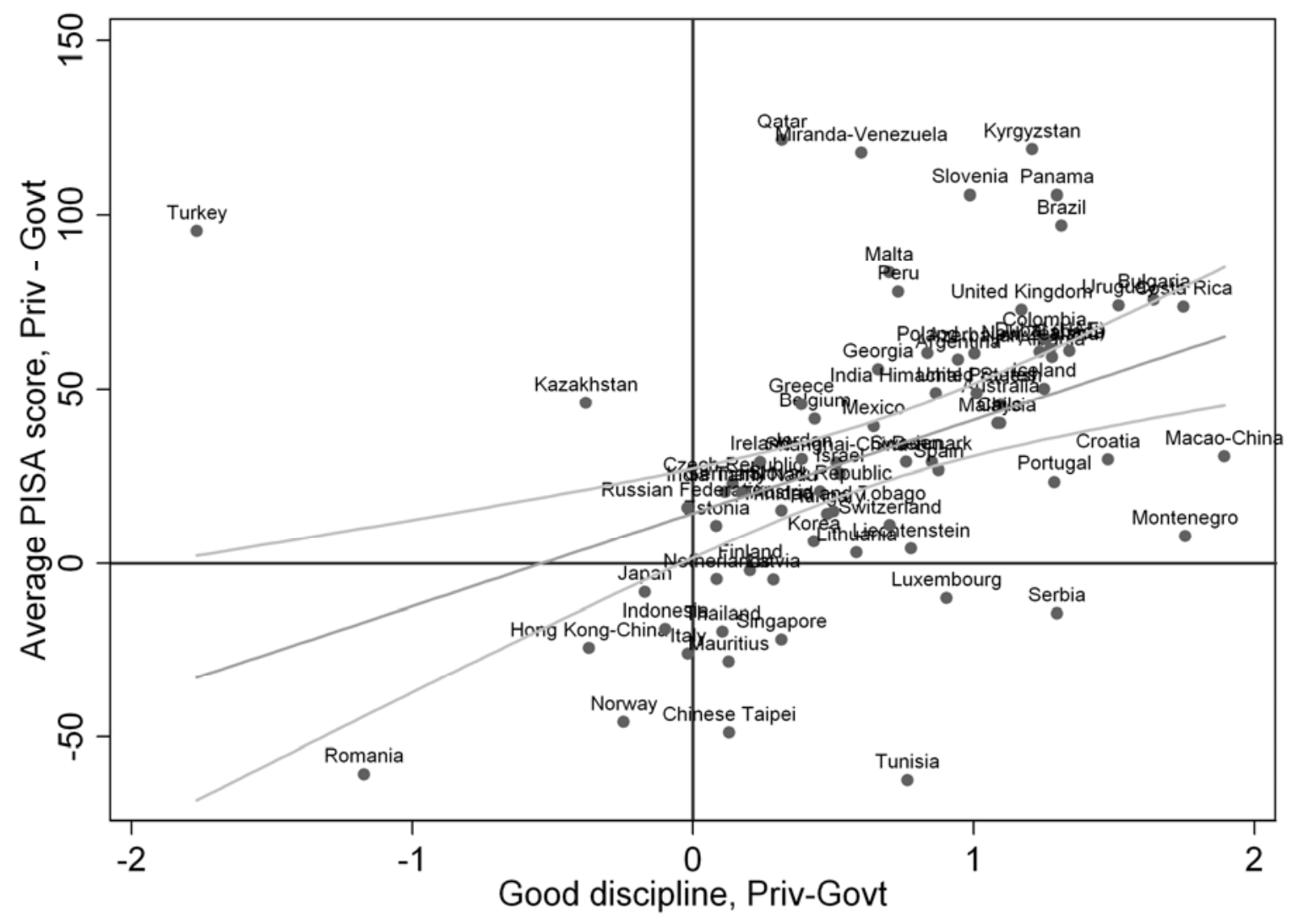

Figure 2e. PISA Scores and Good Discipline, country-specific differences between private and government school averages. All observations are plotted along with a linear regression prediction and 95\% mean confidence intervals. Vertical axis: test scores differential as defined in the note to Figure 1. Horizontal axis: Difference of country-specific averages, within each of the private and government sectors, of variable studbeha, a normalized index of school climate based on indicators of Student absenteeism; Disruption of classes by students; Students skipping classes; Students lacking respect for teachers; Student use of alcohol or illegal drugs; Students intimidating or bullying other students. Higher values code better behaviour; the variable is normalized by OECD to unitary standard deviation and ranges between -3.41 and +2.36 . 


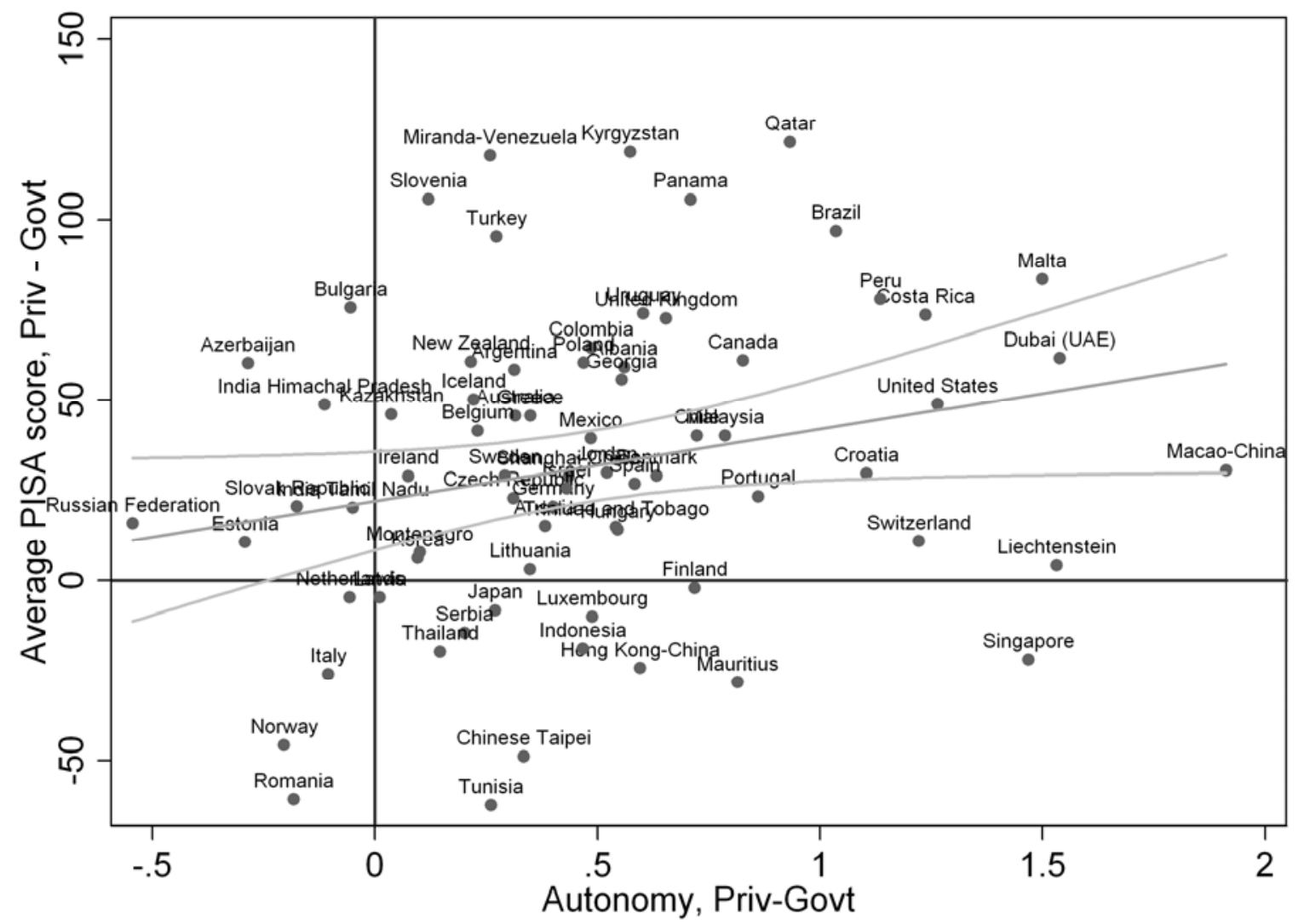

Figure 2f. PISA Scores and Autonomy, country-specific differences between private and government school averages. All observations are plotted along with a linear regression prediction and 95\% mean confidence intervals. Vertical axis: test scores differential as defined in the note to Figure 1. Horizontal axis: Autonomy differential measured from country-specific averages, within each of the private and government sectors, of variable respcurr, a normalized index of school responsibility for curriculum and assessment based on school head indications regarding "Establishing student assessment policies", "Choosing which textbooks are used", "Determining course content", and "Deciding which courses are offered". Higher values code higher levels of school responsibility in this area; the variable is normalized by OECD to unitary standard deviation and ranges between -1.36 and +1.36 . 


\begin{tabular}{|c|c|c|c|c|c|c|c|}
\hline $\begin{array}{l}\text { Country } \\
\text { or sub-national unit }\end{array}$ & $\begin{array}{c}\% \\
\text { private }\end{array}$ & Students & Schools & Масао (China) & 97.08 & 4415 & 45 \\
\hline Albania & 8.6 & 4570 & 181 & Malaysia & 4.17 & 4992 & 152 \\
\hline Azerbaijan & 1.83 & 4643 & 162 & Malta & 41.84 & 3246 & 52 \\
\hline Argentina & 36.64 & 3976 & 189 & Mauritius & 46.11 & 4190 & 182 \\
\hline Australia & 38.83 & 14226 & 353 & Mexico & 11.01 & 36007 & 1530 \\
\hline Austria & 13.64 & 6098 & 234 & Montenegro & 0.81 & 4825 & 52 \\
\hline Belgium & 70.21 & 7866 & 255 & Netherlands & 61.41 & 4553 & 185 \\
\hline Brazil & 12.28 & 17558 & 939 & New Zealand & 5.21 & 4641 & 163 \\
\hline Bulgaria & 1.4 & 4433 & 178 & Norway & 1.22 & 4578 & 197 \\
\hline Canada & 7.14 & 22960 & 974 & Panama & 28.44 & 3281 & 188 \\
\hline Chile & 59.14 & 5015 & 164 & Peru & 20.96 & 5291 & 237 \\
\hline Shanghai (China) & 10.05 & 4854 & 151 & Poland & 6.86 & 4882 & 185 \\
\hline Chinese Taipei & 38.2 & 5824 & 158 & Portugal & 11.36 & 5204 & 214 \\
\hline Colombia & 19.76 & 6775 & 273 & Qatar & 28.99 & 8012 & 151 \\
\hline Costa Rica & 17.09 & 3476 & 178 & Romania & 0.63 & 4776 & 159 \\
\hline Croatia & 1.42 & 4994 & 158 & Russian Fed. & 0.23 & 5217 & 213 \\
\hline Czech Republic & 4.72 & 5725 & 261 & Serbia & 1.01 & 5439 & 190 \\
\hline Denmark & 17.89 & 5819 & 285 & Singapore & 2.4 & 5081 & 171 \\
\hline Estonia & 2.68 & 4664 & 175 & Slovak Republic & 7.69 & 4411 & 188 \\
\hline Finland & 4.77 & 5771 & 193 & Slovenia & 2.1 & 6154 & 341 \\
\hline Georgia & 5.21 & 4566 & 225 & Spain & 41.04 & 23130 & 886 \\
\hline Germany & 5.37 & 4470 & 215 & Sweden & 11.88 & 4563 & 189 \\
\hline Greece & 6.69 & 4920 & 183 & Switzerland & 3.17 & 11548 & 426 \\
\hline Hong Kong & 93.06 & 4366 & 151 & Thailand & 12.98 & 6181 & 230 \\
\hline Hungary & 11.86 & 4545 & 185 & Trinidad Tobago & 15.43 & 4025 & 149 \\
\hline Iceland & 0.64 & 3305 & 131 & Dubai (UAE) & 57.51 & 10114 & 369 \\
\hline Indonesia & 45.91 & 4812 & 181 & Tunisia & 1.77 & 3900 & 164 \\
\hline Ireland & 63.26 & 3386 & 144 & Turkey & 0.7 & 4847 & 150 \\
\hline Israel & 17.44 & 5590 & 176 & United Kingdom & 3.9 & 11545 & 482 \\
\hline Italy & 5.44 & 30109 & 1062 & United States & 6.58 & 5224 & 164 \\
\hline Japan & 27.46 & 6088 & 186 & Uruguay & 20.83 & 4926 & 225 \\
\hline Kazakhstan & 2.6 & 5381 & 199 & Miranda (Venezuela) & 90.23 & 2631 & 121 \\
\hline Jordan & 13.84 & 6408 & 210 & Himachal Pradesh & 16.97 & 1355 & 66 \\
\hline Korea & 38.06 & 4987 & 157 & (India) & & & \\
\hline Kyrgyzstan & 2.19 & 4938 & 173 & Tamil Nadu (India) & 37.62 & 2900 & 147 \\
\hline Latvia & 0.84 & 4395 & 180 & & & & \\
\hline Liechtenstein & 5.52 & 326 & 12 & Total & 18.67 & 476980 & 18029 \\
\hline Lithuania & 0.98 & 4477 & 196 & & & & \\
\hline nbo & 14.48 & 580 & 39 & & & & \\
\hline
\end{tabular}

Table 1. Sample distribution of students by school type and country. Schools surveyed in PISA 2009 are classified as private when variable schtype takes value 2 ("government dependent private schools," controlled by a non-government organization or with a governing board not selected by a government agency, receiving more than 50\% of their core funding from government agencies) or 3 ("government independent private schools," controlled by a non-government organisation or with a governing board not selected by a government agency, receiving less than $50 \%$ of their core funding from government agencies). This information is not available for France and Moldova. Students not in the modal grade \pm 1 year are also dropped from the sample. 


\begin{tabular}{|c|c|c|c|c|c|}
\hline \multirow[b]{2}{*}{ Regressors: } & \multicolumn{5}{|c|}{$\begin{aligned} \text { Dependent variable: } 1 \text { if in Private school, } \\
0 \text { if in government school. }\end{aligned}$} \\
\hline & (1) & (2) & (3) & (4) & (5) \\
\hline \multicolumn{6}{|l|}{$\begin{array}{l}\text { Individual PISA Score } \\
\text { interaction with country: }\end{array}$} \\
\hline \multirow[t]{2}{*}{$\Delta$ Selectivity $10^{-4}$} & -0.4551 & 11.2170 & 35.5220 & 11.2170 & 11.2170 \\
\hline & -0.72 & 0.71 & 1.52 & 0.71 & 0.71 \\
\hline \multirow[t]{2}{*}{$\Delta$ Accountability $10^{-3}$} & 0.8453 & 1.8124 & 0.6447 & 1.8124 & 1.8124 \\
\hline & 9.12 & 1.75 & 0.51 & 1.75 & 1.75 \\
\hline \multirow[t]{2}{*}{$\Delta$ Low Pressure $10^{-3}$} & -0.5823 & -2.7233 & -2.4266 & -2.7233 & -2.7233 \\
\hline & -9.03 & -2.16 & -1.60 & -2.16 & -2.16 \\
\hline \multirow[t]{2}{*}{$\Delta$ Repeaters $10^{-3}$} & -0.0949 & -0.0836 & -0.2210 & -0.0836 & -0.0836 \\
\hline & -12.26 & -1.45 & -2.61 & -1.45 & -1.45 \\
\hline \multirow{2}{*}{$\Delta$ Good Discipline $10^{-3}$} & 0.2438 & -0.0426 & -1.2637 & -0.0426 & -0.0426 \\
\hline & 5.49 & -0.04 & -0.86 & -0.04 & -0.04 \\
\hline \multirow[t]{2}{*}{$\Delta$ Autonomy $10^{-3}$} & 0.5115 & -3.0126 & -4.6040 & -3.0126 & -3.0126 \\
\hline & 8.79 & -2.51 & -2.66 & -2.51 & -2.51 \\
\hline \multicolumn{6}{|l|}{$\begin{array}{l}\text { country } \Delta \text { Fees } 10^{-4} \\
\text { interaction with individual: }\end{array}$} \\
\hline Cultural level & & & $\begin{array}{c}1.4215 \\
0.25\end{array}$ & -2.5416 & -2.5416 \\
\hline \multirow[t]{2}{*}{ Wealth } & & & $\begin{array}{r}9.35 \\
5.7573\end{array}$ & $\begin{array}{c}-1.62 \\
14.6232\end{array}$ & $\begin{array}{l}-1.62 \\
14.6232\end{array}$ \\
\hline & & & 17.49 & 6.59 & 6.59 \\
\hline \multicolumn{6}{|l|}{$\begin{array}{l}\text { country } \Delta \text { Low Pressure } 10^{-3} \\
\text { interaction with individual: }\end{array}$} \\
\hline \multirow[t]{4}{*}{ Cultural level } & & & -16.0734 & 93.7160 & 93.7160 \\
\hline & & & -8.15 & 2.33 & 2.33 \\
\hline & & & -14.8801 & -178.1112 & -178.1112 \\
\hline & & & -3.84 & -3.46 & -3.46 \\
\hline \multirow{2}{*}{$\begin{array}{r}\text { country } \Delta \text { Autonomy } 10^{-3} \\
\text { interaction with individual: } \\
\text { City size }\end{array}$} & & & & & \\
\hline & & & & & $\begin{array}{c}500.7585 \\
0.91\end{array}$ \\
\hline Controls & (a) & (b) & (a) & (b) & (b) \\
\hline Observations & 476980 & 466957 & 462193 & 461070 & 461070 \\
\hline Parameters & 78 & 473 & 145 & 465 & 465 \\
\hline Residual SS & $4.93 e+04$ & $4.16 \mathrm{e}+04$ & $4.59 e+04$ & $4.10 \mathrm{e}+04$ & $4.10 \mathrm{e}+04$ \\
\hline
\end{tabular}

Table 2. Individual private school choice across countries. Coefficients from a linear probability model of interactions between individual covariates and the $\Delta$ private-government countrylevel average differences of the indicators defined in the legends of Figures 1 and 2a-f. For legibility the differences displayed in those figures are rescaled, by $10^{-3}$ or $10^{-4}$ as indicated, before running these regressions. Coefficient not reported for additional controls: (a) country fixed effects and pooled main effect of individual PISA score; (b) country fixed effects and country specific main effects of PISA Score and of Gender, Vocational, City size, Cultural level, Wealth (see the main text for definitions). The $t$ statistics in italics allow for error clustering at the country and schoolid level. 